\title{
Cinesioritmoterapia: Exploração das Possibilidades de Movimento, Som e Ritmo para Promoção da Consciência Corporal, Interação Social e Autonomia na Saúde Mental.
}

\author{
Nascimento, Maria Helena Ferreira do; Ueno, Neusa Hetsuko Kaneko; Nishimori, \\ Yukiko; Guimarães, Maria Helena; Ribeiro, Eni; Takeda, Osvaldo Hakio \\ Hospital Dia do IPqHCFMUSP — helena_nascimento2004@ig.com
}

Introdução: Observando prejuízos decorrentes de enfermidades mentais como lentificação motora, falta de motivação, marchas dificultadas, falas em baixo tom, olhar sem foco, isolamento, falta de iniciativa, pensou-se em elaborar uma atividade que envolvesse o movimento e ritmo corporal. a partir dessa constatação, reflexões, estudos e parceria com uma renomada profissional de dança, que utiliza o movimento como forma terapêutica foi criada a Cinesioritmoterapia. Essa abordagem terapêutica se utiliza da exploração corporal voltada ao autoconhecimento, estimulação do movimento criativo e a espontaneidade do corpo, envolvendo a união de várias técnicas corporais visando a integração do movimento, ritmo, dança e sons. Objetivo: Oferecer um espaço de vivência e percepção corporal, com o uso de estruturas corporais pouco estimuladas. Proporcionar integração social, física e mental . Desenvolver nos pacientes o reconhecimento de cada estrutura do próprio corpo. Método: As atividades são conduzidas por terapeutas corporais, realizadas semanalmente por um período de 1 hora. 0 grupo atendido é formado por pacientes adultos com transtornos mentais graves vinculados a instituição pública de saúde mental. a metodologia utiliza os movimentos corporais para explorar formas expressivas de trabalhar a respiração, uma vez que alguns sintomas são manifestados por meio de movimentos respiratórios. Durante as atividades são utilizados recursos como flexibilidade, coordenação, ritmo, equilíbrio, espaço e sons, para promover interação e socialização. Tal técnica tem como base os princípios desenvolvidos no método de Rudolf Laban, Wilhelm Reich e Alexander Lowen. Resultado: o trabalho vem sendo desenvolvido há 1 ano e meio, observa-se alterações comportamentais, emocionais e físicas: melhora da consciência corporal e espacial, mímica e expressões mais adequadas, interação social, melhora psicomotora e iniciativa. a alegria e o entusiasmo em participar dos grupos conduzem para a descoberta do "eu posso". Conclusão: o ritmo e o movimento como ferramentas terapêuticas apresentam resultados benéficos para a saúde física e mental para essa população de pacientes. Os benefícios observados estão em constante evolução, a cada atividade os pacientes tem a oportunidade de se desenvolver de forma nova e particular. com o aumento da auto-estima, autonomia pessoal, e consciência corporal, ocorre um desbloqueio de sentimentos e pensamentos oprimidos e recorrentes, de modo que a capacidade de conduzir suas atividades da vida diária, passa a se fazer de maneira humanizada e acolhida, aliviando as sensações de medo e insegurança na relação com o outro, anteriormente impensadas. a mente e o corpo são únicos e atingem o progresso a partir da expansão da consciência, que deixa aflorar o potencial de cada indivíduo, fazendo emergir a análise de sua história de vida. É a partir dai que o trabalho corporal passa a ter, de fato, sentido no contexto terapêutico.

Nascimento, Maria Helena Ferreira do; Ueno, Neusa Hetsuko Kaneko; Nishimori, Yukiko; Guimarães, Maria Helena; Ribeiro, Eni; Takeda, Osvaldo Hakio. Cinesioritmoterapia: Exploração das Possibilidades de Movimento, Som e Ritmo para Promoção da Consciência Corporal, Interação Social e Autonomia na Saúde Mental.. In: Anais do Congresso Internacional de Humanidades \& Humanização em Saúde [= Blucher Medical Proceedings, num.2, vol.1]. São Paulo: Editora Blucher, 2014. ISSN 2357-7282 DOI 10.5151/medpro-cihhs-10669 